\title{
Seasonal variation of particle size distributions of PAHs at Seoul, Korea
}

\author{
Ji Yi Lee • Hye Jung Shin • Soo Ya Bae • \\ Yong Pyo Kim • Chang-Hee Kang
}

Received: 24 October 2007 / Accepted: 18 February 2008 / Published online: 14 March 2008

(C) Springer Science + Business Media B.V. 2008

\begin{abstract}
The atmospheric size distributions of particulate polycyclic aromatic hydrocarbons (PAHs) up to $10 \mu \mathrm{m}$ in diameter were measured at Seoul in the summer and winter of 2003. The concentrations of total PAHs were from 4.32 to $5.48 \mathrm{ng} \mathrm{m}^{-3}$ in summer and from 25.6 to $35.9 \mathrm{ng} \mathrm{m}^{-3}$ in winter, respectively. Majority of the PAHs concentrations were found on fine particles $\left(D_{\mathrm{p}}<2.1 \mu \mathrm{m}\right)$. The size distributions of individual PAH compounds were bimodal with
\end{abstract}

\author{
J. Y. Lee • H. J. Shin · S. Y. Bae • Y. P. Kim $(\bowtie)$ \\ Department of Environmental Science and Engineering, \\ Ewha Womans University, \\ 11-1 Daehyun-dong, Seodaemun-gu, \\ Seoul 120-750, South Korea \\ e-mail: yong@ewha.ac.kr \\ J. Y. Lee \\ e-mail: yijiyi@ewha.ac.kr \\ H. J. Shin \\ e-mail: shjoung@me.go.kr \\ S. Y. Bae \\ e-mail: sbae@ewhain.net \\ H. J. Shin \\ Air Quality Division, \\ National Institute of Environmental Research, \\ Kyungseo-dong, Seo-gu, \\ Incheon 404-708, South Korea \\ C.-H. Kang \\ Department of Chemistry, Cheju National University, \\ 1 Aradong, \\ Jeju 690-756, South Korea \\ e-mail: changhee@cheju.cheju.ac.kr \\ Present address: \\ J. Y. Lee \\ Air Quality Research Division, Environment Canada, \\ 4905 Dufferin St., \\ Toronto, ON M3H 5T4, Canada
}

the peaks in the $0.43-0.65-$ and $4.7-5.8-\mu \mathrm{m}$ range in summer. In winter, those were unimodal or weakly bimodal with the peaks in the 0.65-1.1- and 4.7-5.8- $\mu \mathrm{m}$ range. The seasonal variation of the peak size range in the fine mode might be caused by longer residence time in the air in winter. Based on the previously reported source diagnostic ratios of PAHs for the major emission sources, it was suggested that vehicles were the major source of PAH in summer, while coal-related emissions and firewood fire were the major sources in winter for fine particles. The seasonal variation of the peak size ranges in the fine particles had not shown noticeable effect on the dry deposition fluxes. However, it might affect the optical properties of the atmosphere.

Keywords Bimodal distribution .

Molecular weight dependency · Dry deposition .

Optical properties

\section{Introduction}

Polycyclic aromatic hydrocarbons (PAHs) are ubiquitous organic pollutants, some of which are reported to be mutagenic and carcinogenic materials (Agency for Toxic Substances and Disease Registry 1995). PAHs are one of the considered persistent toxic substances (PTS) in central and northeast Asia (Region VII) designated in the Stockholm convention (United Nations Environment Programme 2002). PAHs are mainly formed during incomplete combustion processes of organic matter such as coal, wood, gasoline, or diesel fuel. Soot particles can be viewed as a mixture of elemental carbon (EC; also called black carbon), organic carbon (OC), and small amounts of other elements such as nitrogen. PAHs were considered as the main molecular 
intermediates for soot formation and growth (Seinfeld and Pandis 1998). Thus, understanding atmospheric transport processes of PAHs may help to understand the behavior of soot particles.

Particle size is an important factor determining the behavior of particles in the atmosphere and influences inhalation exposure. For example, deposition flux of particles is a strong function of particle size (Offenberg and Baker 1999). Therefore, the particle size distributions of an individual PAH compound can provide information on major emission sources of the PAHs, residence time in the atmosphere, and the health effect of PAHs.

Higher-molecular-weight (MW) PAHs, due to their lower vapor pressures than lower-MW PAHs, show lower fluxes for volatilization and condensation, and thus, their characteristic time to partition to larger particles is much longer than that for the lower MW PAHs. Therefore, PAHs tend to remain to fine particles under a low-ambient temperature condition and at sites close from emission sources. In addition, PAHs size distributions in the atmosphere are influenced by the growth of combustion-generated particles and the variation of PAHs adsorption and absorption affinity based on particle size-dependent physical characteristics and chemical composition (Venkataraman and Friedlander 1994; Allen et al. 1996).

Particle size distributions of PAHs have been mainly studied in Europe and North America (Offenberg and Baker 1999; Allen et al. 1996; Venkataraman and Friedlander 1994; Aceves and Grimalt 1993; Sicre et al. 1987; Miguel and Friedlander 1978; van Vaeck and van Cauwenberghe 1978; Pierce and Katz 1975). In these studies, PAH were predominantly associated with fine particle $\left(D_{\mathrm{p}}<2.5 \mu \mathrm{m}\right)$, and PAH compounds with the same MW were generally observed in the similar particle size range. Recently, there have been several studies for particle size distribution of PAHs in Northeast Asia (Bi et al. 2005; Zhou et al. 2005; Kawanaka et al. 2004). They also reported that PAHs were associated with fine particle $\left(D_{\mathrm{p}}<2.5 \mu \mathrm{m}\right)$, and the fraction of PAHs associated with larger aerosols increased as MW decreased.

Seoul is the capital city of the Republic of Korea with 10 million inhabitants and 2.5 million vehicles. Korea is surrounded by China and Japan. Thus, Seoul might be influenced by transport of air pollutants from these areas in addition to local sources. For example, Lee and Kim (2007) applied the chemical mass balance (CMB) model for the particulate PAH samples between 2002 and 2003. They found that transport from outside the Seoul metropolitan area was significant, especially in winter. In Seoul, only two studies have been reported on the size distributions of PAHs in Korea (Lee et al. 2006a; Bae et al. 2002). They found that most PAHs were in small particles $\left(D_{\mathrm{p}}<9 \mu \mathrm{m}\right)$. Furthermore, they observed that the ambient PAH concentrations in the rural areas were comparable to those in the urban areas in Korea. They suggested that there might be local emission sources of PAHs in rural areas in Korea in addition to the transport from urban areas. However, they could not observe meaningful seasonal difference of the particle size distribution of PAHs.

In this study, the particles size distributions of PAHs were measured at Seoul, a representative urban area in Korea in the summer and winter of 2003 (1) to characterize the seasonal variation of the particle size distribution of particulate matter smaller than $10 \mu \mathrm{m}$ in aerodynamic diameter (PM10) and PAHs in Seoul, (2) to determine the major factor affecting the seasonal variation of the observed particle size distributions of PAHs, and (3) to discuss the effect of particle size distribution on the aerosol properties.

\section{Experiment}

Measurements were carried out in June and December, 2003, at Seoul in Korea. A summary of the sampling conditions is provided in Table 1. The sampling site in Seoul is located in Asan hall, Ewha Womans University.

Table 1 Summary of the sampling and meteorological conditions in 2003 at Seoul

\begin{tabular}{|c|c|c|c|c|c|c|c|}
\hline Season & Sample name & Sampling date & $\begin{array}{l}\text { Average } \\
\text { temp. }\left({ }^{\circ} \mathrm{C}\right)\end{array}$ & $\begin{array}{l}\text { Average } \\
\text { wind speed }\left(\mathrm{m} \mathrm{s}^{-1}\right)\end{array}$ & $\begin{array}{l}\text { Relative } \\
\text { humidity (\%) }\end{array}$ & $\begin{array}{l}\text { PM10 } \\
\text { concentration } \\
\left(\mu \mathrm{g} \mathrm{m}^{-3}\right)\end{array}$ & $\begin{array}{l}\text { Total PAHs } \\
\text { concentration } \\
\left(\mathrm{ng} \mathrm{m}^{-3}\right)\end{array}$ \\
\hline \multirow[t]{3}{*}{ Summer } & S-1 & 6-9 June & 21 & 1.6 & 63 & 75.8 & 5.97 \\
\hline & S-2 & 9-11 June & 23 & 1.6 & 60 & 65.1 & 4.75 \\
\hline & S-3 & 16-19 June & 22 & 1.7 & 72 & 117 & 5.78 \\
\hline \multirow[t]{5}{*}{ Winter } & $\mathrm{W}-1$ & 3-5 December & 2.2 & 1.8 & 44 & 65.7 & 27.5 \\
\hline & $\mathrm{W}-2$ & 9-11 December & -1.6 & 1.6 & 50 & 83.0 & 38.0 \\
\hline & W-3 & 12-15 December & 0.7 & 2.0 & 63 & 68.0 & 26.8 \\
\hline & W-4 & 18-21 December & -4.5 & 3.1 & 47 & 45.5 & 27.4 \\
\hline & W-5 & 23-26 December & 3.7 & 2.1 & 87 & 223 & 35.4 \\
\hline
\end{tabular}


Samples were collected on a 3-m-high platform on the roof of Asan hall, a five-story building of $15 \mathrm{~m}$ height. It is adjacent to a road in the west, Mt. Ansan in the north, and stands on a hill commanding the campus.

The size distributions of PM10 were measured for 48 or $72 \mathrm{~h}$ on prefired quartz fiber filters (QFFs, QM-A, Whatman) by an eight-stage Andersen 1 ACFM Nonviable Ambient Cascade Impactor equipped with a size-selective inlet. Aerosol particles were separated into eight fractions (eight stages and a backup filter), resulting in size ranges of 10-9, 9-5.8, 5.8-4.7, 4.7-3.3, 3.3-2.1, 2.1-1.1, 1.1-0.65, $0.65-0.43$, and less than $0.43 \mu \mathrm{m}$ in diameter. Filters were conditioned in a dessicator (room temperature and $40 \%$ relative humidity) for $24 \mathrm{~h}$ before weighing. The balance used was with the accuracy of $0.01 \mathrm{mg}$.

The analytical procedures used in this study were described in detail in Lee et al. (2006b). Size segregated particulate PAH samples collected on the QFFs were extracted by ultrasonication with dichloromethane solvent. The extracts were filtrated through a $0.45-\mu \mathrm{m}$-pore size syringe filter. The above extraction procedure has been repeated three times for the residual sample filters. Then, the extracts were concentrated at $20^{\circ} \mathrm{C}$ to a volume of $1 \mathrm{~mL}$ using an evaporator (Zymark, Turbovap 500). Then, phenanthrene- $\mathrm{D}_{10}$ was added to each concentrated sample solution as an internal standard for analysis.

Seventeen PAH compounds were identified and quantified using a Hewlett Packard 5890 gas chromatograph (GC) equipped with a 5972 mass selective detector (MSD). The MSD was run in selected ion-monitoring mode. The compounds were separated with a splitless injection into a $25 \mathrm{~m} \times 0.22$-mm-inside diameter ultra-2 chromatographic column with a $0.33-\mu \mathrm{m}$ film thickness. Helium was the carrier gas and was operated at a $0.9 \mathrm{~mL} \min ^{-1}$. The injector and detector were maintained at $270^{\circ} \mathrm{C}$ and $310^{\circ} \mathrm{C}$, respectively. The GC temperature program was $50^{\circ} \mathrm{C}$ for $2 \mathrm{~min}, 17^{\circ} \mathrm{C} \mathrm{min}{ }^{-1}$ to $260^{\circ} \mathrm{C}, 260^{\circ} \mathrm{C}$ for $1 \mathrm{~min}, 10^{\circ} \mathrm{C} \mathrm{min}^{-1}$ to $310^{\circ} \mathrm{C}$, and maintained for 15 minutes. The sample injection volume was $2 \mu \mathrm{L}$. The names of the analyzed PAH compounds and their abbreviations are given in Table 2. The QFF field blanks were prepared and analyzed for each set of field samples with the same procedure.

For quantification, response factors of seventeen individual compounds in the standard solution with respect to phenenthrene- $\mathrm{D}_{10}$ were calculated, and then calibration curves (response factors vs. PAH concentrations) were drawn for each compound. The standard solution for calibration was prepared by diluting the Supelco stock solution (Supelco, EPA 610 Polynuclear Aromatic Hydrocarbons Mixture) containing $16 \mathrm{PAH}$ compounds except benzo(e)pyrene $(\mathrm{BeP})$ and the Aldrich $\mathrm{BeP}$ solution (Aldrich, B1010-2). Method detection limits (MDLs) were determined as the three standard deviations of the field blank analysis results, and the MDL values of individual PAH compounds were less than all the sample masses of individual compounds. The blank values were accounted for the concentration calculation.

The mean extraction recoveries for particulate PAHs range from $72 \%$ to $98 \%$, and these recoveries are accounted for in the concentration calculation. The accuracy of the analytical procedure was tested through the analysis of National Institute of Standards and Technology (NIST, USA) standard reference materials (SRM) 1649 urban dust sample. The extraction recoveries and analytical accuracy results for the SRM 1649 samples are also presented in Table 2.
Table 2 Particulate PAHs extraction recovery and analysis result of the NIST SRM-1649 urban dust sample in this study

\begin{tabular}{lllll}
\hline PAH compounds & Abbrev. & Recovery $(\%)$ & $\begin{array}{l}\text { Certified value } \\
\left(\mu \mathrm{kg}^{-1}\right)\end{array}$ & $\begin{array}{l}\text { Measured value } \\
\left(\mu \mathrm{gg}^{-1}\right)\end{array}$ \\
\hline Naphthalene & Naph & 92 & - & - \\
Acenaphtylene & Acy & 87 & - & - \\
Acenaphthene & Ace & 82 & - & - \\
Fluorene & Flu & 85 & - & - \\
Phenanthrene & Phen & 98 & $4.14 \pm 0.37$ & $4.67 \pm 0.49$ \\
Antracene & Anthr & 83 & $0.43 \pm 0.08$ & $0.46 \pm 0.06$ \\
Fluoranthene & Flt & 91 & $6.45 \pm 0.18$ & $5.50 \pm 0.18$ \\
Pyrene & Pyr & 85 & $5.29 \pm 0.25$ & $4.37 \pm 0.22$ \\
Benzo(a)anthracene & BaA & 93 & $2.21 \pm 0.07$ & $1.84 \pm 0.59$ \\
Chrysene & Chry & 72 & $3.05 \pm 0.06$ & $3.67 \pm 0.54$ \\
Benzo(b)fluoranthene & BbF & 83 & $6.45 \pm 0.64$ & $5.43 \pm 0.40$ \\
Benzo(k)fluoranthene & BkF & 88 & $1.91 \pm 0.03$ & $2.27 \pm 0.29$ \\
Benzo(e)pyrene & BeP & 84 & - & - \\
Benzo(a)pyrene & BaP & 96 & $2.51 \pm 0.09$ & $2.92 \pm 0.82$ \\
Indeno(1,2,3-cd)pyrene & Ind & 98 & $3.18 \pm 0.72$ & $2.87 \pm 0.66$ \\
Dibenz(a,h)anthracene & DahA & 97 & $0.29 \pm 0.02$ & $0.35 \pm 0.04$ \\
Benzo(g,h,i)perylene & BghiP & 94 & $4.01 \pm 0.91$ & $3.68 \pm 0.69$ \\
\hline
\end{tabular}


In this study, 17 PAH compounds were identified and quantified. However, naphthalene, acenaphthene, acenaphtylene, and fluorene exist predominantly in the gas phase in the atmosphere. Because the major focus of this study is on the particulate $\mathrm{PAH}$ concentration, these compounds are excluded for further data analysis.

\section{Results}

Aerosol mass size distribution

The average PM10 concentration in summer was $85.8 \mu \mathrm{g} \mathrm{m}^{-3}$ ranged from 65.1 to $117 \mu \mathrm{g} \mathrm{m}^{-3}$ and in winter was $97.0 \mu \mathrm{g} \mathrm{m}^{-3}$ from 45.5 to $223 \mu \mathrm{g} \mathrm{m}^{-3}$, respectively. The highest concentration of PM10 $\left(223 \mathrm{\mu g} \mathrm{m}^{-3}\right)$ was observed in 23-26 December, 2003 (Sample number W-5 in Table 1). The level of PM10 concentrations at Seoul was about two times higher than the level of PM11 at the urban area in Japan (42 $\mu \mathrm{g} \mathrm{m}^{-3}$, Kawanaka et al. 2004) while one third lower than those at the urban area in Guangzhou, China $\left(288.8 \mu \mathrm{g} \mathrm{m}^{-3}\right.$, Bi et al. 2005). The PM10 level at Seoul was comparable

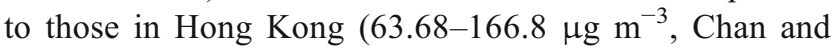
Kwok 2000).

Figure 1 shows the average size distributions of PM10 in (a) summer and (b) winter. In winter, the PM10 concentrations of the W-5 sample was very high with the unusual meteorological conditions, and the average size distribution of PM10 including the W-5 sample in winter was different with those excluding the W-5 sample in winter (Fig. 1b). Thus, to characterize the general size distribution in winter, the $\mathrm{W}-5$ result was excluded in further data analysis. Seasonal variation of PM10 concentrations was not observed. Furthermore, the size distributions of PM10 in summer and winter were similar. The PM10 size distribution was bimodal with the peaks in the $0.65-1.1-\mu \mathrm{m}$ size range in the fine mode and $4.7-5.8-\mu \mathrm{m}$ in the coarse mode, respectively, a typical size distribution for an urban atmosphere.
Figure 2 shows the PM10 and PAH size distribution of the W-5 sample. Compared to the average PM size distribution for winter except W-5 (solid line in Fig. 1b), the peak in fine mode in $\mathrm{W}-5$ was in the $1.1-2.1-\mu \mathrm{m}$ size range, larger than the winter average $(0.65-1.1-\mu \mathrm{m}$ in diameter). The PM10 concentration of W-5 was $223 \mu \mathrm{g} \mathrm{m}^{-3}$, three times higher than the average PM10 concentration of other winter samples except W-5 and comparable to that measured at urban area in China (Bi et al. 2005).

This high level of PM10 was mainly caused by the meteorological conditions as shown in Table 1. The relative humidity during W-5 was higher than those in other sampling days in winter. It was foggy during the sampling period of W-5, and the air parcels was relatively stagnant according to the backward trajectory analysis result. Thus, there was enough time for particles to grow. In addition, the high relative humidity condition made hygroscopic particles absorb water vapor and gain mass.

Pandis et al. (1990) simulated the aerosol-cloud-aerosol cycle during fog processing of an urban aerosol population. In their simulation, the peak around $1 \mu \mathrm{m}$ in diameter in the mass size distribution of PM before a fog episode was shifted to the peak large than $1 \mu \mathrm{m}$ in diameter. Thus, the size distribution of PM10 in W-5 seems to be the particle growth in fine mode due to the fog episode and the stagnation of the air parcels during the W-5 sampling period.

Although the PM10 concentration for the W-5 sample was three times higher than those for other samples in the winter, the PAH concentration for the W-5 sample was similar to other samples in winter as shown Table 1. As shown in Fig. 2, however, the size distribution of PAHs for the W-5 sample was different with the average PAH size distribution in winter (Fig. 4). The PAH peak in the fine mode for W-5 was larger than the average size distribution as well as the PM10 size distributions. This is also due to the particle growth in the fine mode during a foggy day; thus, the peak range of PAHs shifted from $0.65-1.1-$ to $1.1-2.1-\mu \mathrm{m}$ size ranges.
Fig. 1 Averaged size distributions of PM10 in a summer and b winter
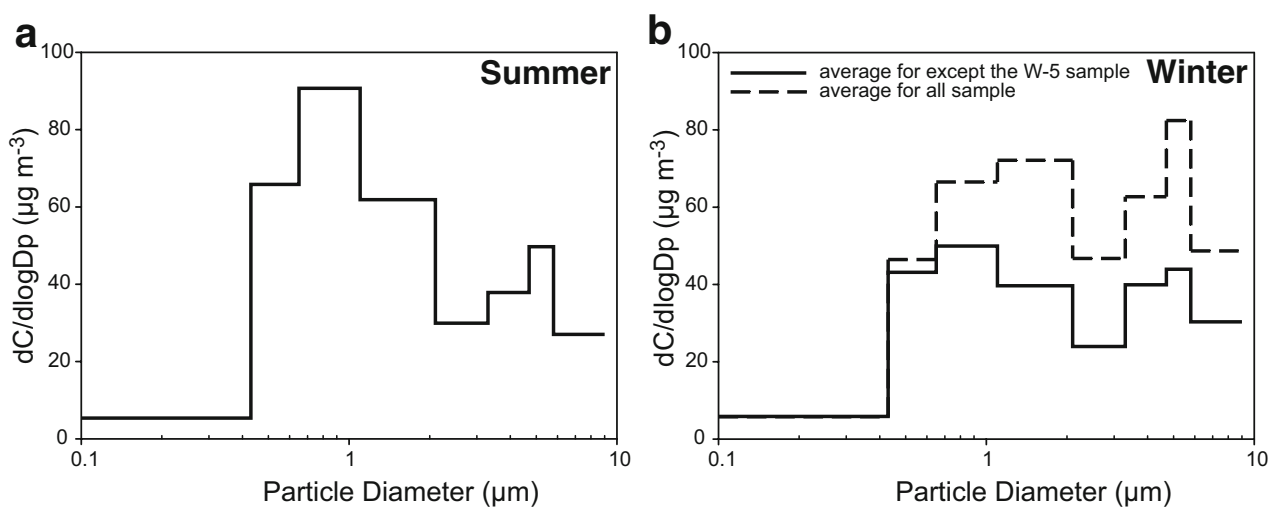
Fig. 2 The size distributions of PM10 and PAHs measured in $\mathrm{W}-5$ in winter

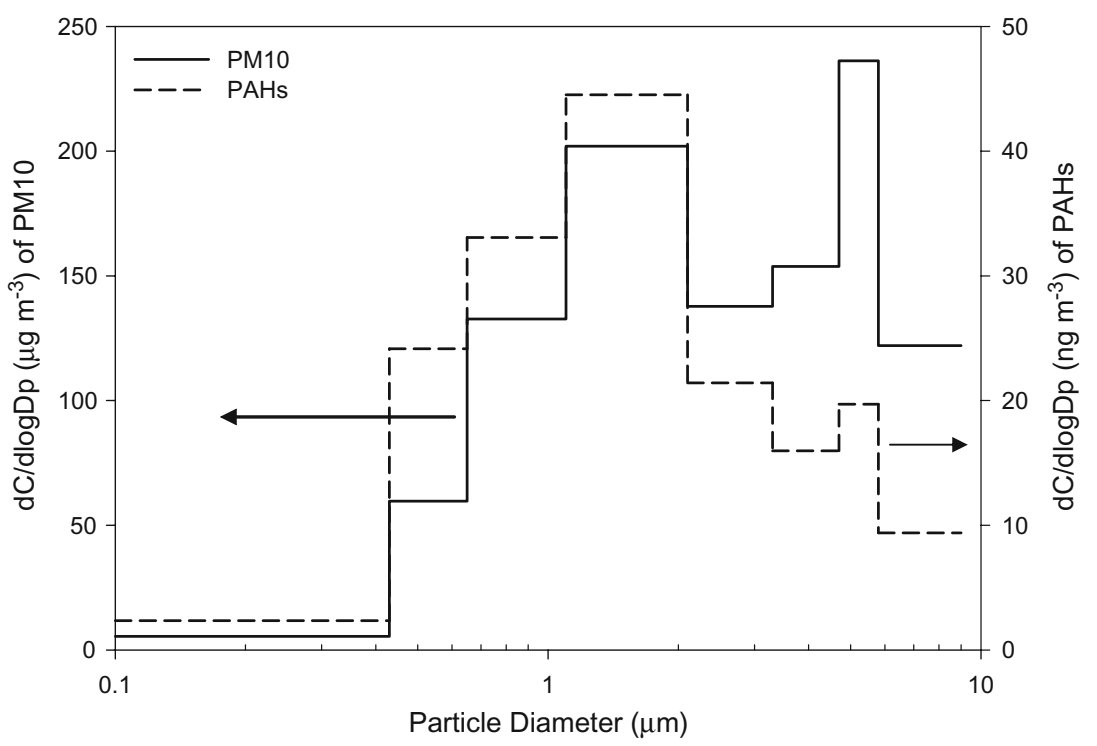

PAH size distribution

The concentrations of total PAHs were ranged from 4.32 to $5.48 \mathrm{ng} \mathrm{m}^{-3}$ in summer and from 25.6 to $35.9 \mathrm{ng} \mathrm{m}^{-3}$ in winter, respectively. The PAHs concentrations in winter were about one order higher than those in summer. For both seasons, about a half (41-65 wt\%) of the PAH concentrations were found on submicrometer particles $\left(D_{\mathrm{p}}<1.1 \mu \mathrm{m}\right)$ and average $75 \mathrm{wt} \%$ on fine particles $\left(D_{\mathrm{p}}<\right.$ $2.1 \mu \mathrm{m})$ as shown in Table 3 .

Figure 3 shows the average size distributions of five representative individual PAH compounds (from low-MW [178] to high-MW [276] PAH compounds) and total PAHs (the sum of 13 compounds' concentrations) in summer. For simplicity, we showed five cpmpounds: phenanthrene (Phen, three-ring, MW=178), fluoranthene (Flt; four-ring, $\mathrm{MW}=202$ ), chrysene (Chry; four-ring, $\mathrm{MW}=228$ ), BeP (five-ring, $\mathrm{MW}=252$ ), and $\operatorname{Benzo}(\mathrm{g}, \mathrm{h}, \mathrm{i})$ perylene (BghiP; six-ring, $\mathrm{MW}=276$ ). The size distributions of individual PAH compounds were bimodal with the peaks in the $0.43-0.65-\mu \mathrm{m}$ size range in the fine mode and 4.7$5.8-\mu \mathrm{m}$ in the coarse mode. Generally, the fine mode can be further divided into two modes: the condensation mode with a peak around $0.2 \mu \mathrm{m}$ in diameter and the droplet mode with a peak around $0.7 \mu \mathrm{m}$ in diameter. The condensation mode is the result of condensation and/or coagulation of freshly emitted aerosols and secondary aerosol components. The droplet mode is attributed to heterogeneous aqueous-phase reactions (Seinfeld and Pandis 1998). The peaks in the $0.43-0.65-\mu \mathrm{m}$ size range observed in summer were between the condensation and droplet modes. Thus, the peaks in summer suggest slightly aged PAHs particles mixed with other compounds through condensation or coagulation.
Table 3 The mass fraction of individual PAH compounds (unit: \%)
${ }^{a}$ Submicrometer: $D_{\mathrm{p}}<1.1 \mu \mathrm{m}$

${ }^{\mathrm{b}}$ Fine: $D_{\mathrm{p}}<2.1 \mu \mathrm{m}$

${ }^{\mathrm{c}}$ Coarse: $2.1<D_{\mathrm{p}}<10 \mu \mathrm{m}$

\begin{tabular}{|c|c|c|c|c|c|c|}
\hline & \multicolumn{3}{|l|}{ Summer } & \multicolumn{3}{|l|}{ Winter } \\
\hline & Submicrometer $^{\mathrm{a}}$ & Fine $^{b}$ & Coarse $^{c}$ & Submicrometer & Fine & Coarse \\
\hline Phen & $58 \pm 9$ & $69 \pm 2$ & $31 \pm 2$ & $46 \pm 7$ & $73 \pm 3$ & $27 \pm 3$ \\
\hline Anthr & $47 \pm 4$ & $63 \pm 6$ & $37 \pm 6$ & $32 \pm 13$ & $47 \pm 20$ & $53 \pm 20$ \\
\hline Flt & $69 \pm 14$ & $82 \pm 5$ & $18 \pm 5$ & $54 \pm 5$ & $83 \pm 1$ & $17 \pm 1$ \\
\hline Pyr & $50 \pm 21$ & $82 \pm 6$ & $18 \pm 6$ & $55 \pm 4$ & $82 \pm 1$ & $18 \pm 1$ \\
\hline $\mathrm{BaA}$ & $67 \pm 5$ & $82 \pm 4$ & $18 \pm 4$ & $47 \pm 2$ & $64 \pm 1$ & $36 \pm 1$ \\
\hline Chry & $71 \pm 8$ & $84 \pm 6$ & $16 \pm 6$ & $65 \pm 7$ & $97 \pm 3$ & $3 \pm 3$ \\
\hline $\mathrm{BbF}$ & $63 \pm 17$ & $74 \pm 12$ & $26 \pm 12$ & $50 \pm 2$ & $70 \pm 2$ & $30 \pm 2$ \\
\hline $\mathrm{BkF}$ & $52 \pm 14$ & $71 \pm 17$ & $29 \pm 17$ & $67 \pm 3$ & $97 \pm 3$ & $3 \pm 3$ \\
\hline $\mathrm{BeP}$ & $67 \pm 16$ & $80 \pm 17$ & $20 \pm 17$ & $54 \pm 5$ & $83 \pm 10$ & $17 \pm 10$ \\
\hline $\mathrm{BaP}$ & $38 \pm 10$ & $51 \pm 8$ & $49 \pm 8$ & $49 \pm 8$ & $66 \pm 11$ & $34 \pm 11$ \\
\hline Ind & $62 \pm 6$ & $76 \pm 11$ & $24 \pm 11$ & $44 \pm 3$ & $62 \pm 3$ & $38 \pm 3$ \\
\hline DahA & $44 \pm 9$ & $57 \pm 9$ & $43 \pm 9$ & $35 \pm 7$ & $49 \pm 6$ & $51 \pm 6$ \\
\hline BghiP & $71 \pm 3$ & $82 \pm 7$ & $18 \pm 7$ & $69 \pm 8$ & $96 \pm 8$ & $4 \pm 8$ \\
\hline Total & $59 \pm 8$ & $73 \pm 9$ & $27 \pm 9$ & $50 \pm 3$ & $74 \pm 2$ & $26 \pm 2$ \\
\hline
\end{tabular}


Fig. 3 Average size distribution of PAH compounds and total PAHs measured in summer
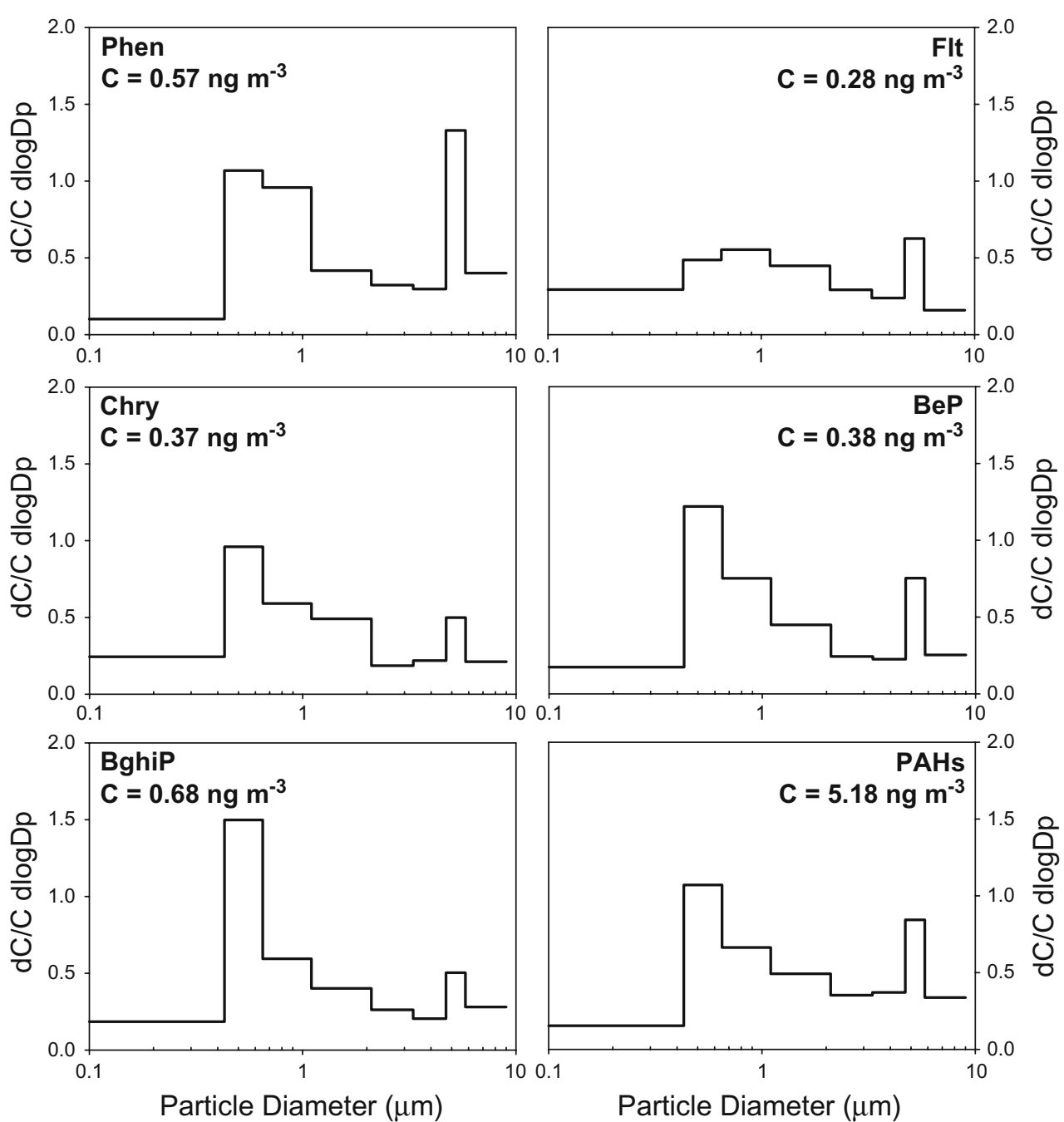

Figure 3 also shows that the mass fractions of the peak size show different trend by MW of the PAH compounds. The mass fractions of the peak range in the fine mode for higher-MW PAH compounds were higher than those for the lower-MW PAH compounds. On the contrary, in the coarse mode, the mass fractions of the peak size range for lowerMW PAH compounds were higher than higher-MW PAH compounds. The same trend was also observed in other studies (Bi et al. 2005; Allen et al. 1996). It indicates that the difference of gas-to-particle partitioning in the atmosphere due to the difference of MW might affect the size distribution of PAH compounds. Lower-MW PAH compounds such as Phen and Flt with higher vapor pressures have higher tendency to volatilize and, therefore, can easily shift toward larger particle size compared to the higher-MW PAH compounds.

Generally, the average size distributions of individual PAH compounds in winter (Fig. 4) were unimodal or weakly bimodal with the peak in the $0.65-1.1-\mu \mathrm{m}$ size range in the fine mode and in the 4.7-5.8- $\mu \mathrm{m}$ range in the coarse mode, respectively. The less prominent peak in the coarse mode in winter can be attributed to the lower ambient temperature and, thus, weak particle-to-gas phase volatilization compared to the summer samples. The peak range $(0.65-1.1-\mu \mathrm{m})$ in the fine mode during winter for all compounds was larger than that in summer and in the droplet mode size. This tendency was observed for all PAH compounds and thus not caused by the different chemical properties among the PAH compounds due to MW. This result can be explained by two factors: higher condensation amount of aged PAHs due to longer residence time in the atmosphere or resize distribution of PAHs after cloud processing.

The PAH level in Seoul can be influenced by air pollutants from outside transport in addition to the local emissions (Lee and Kim 2007). Air parcel trajectories were calculated from the HYSPLIT (Hybrid Single-Particle Lagrangian Integrated Trajectory) model (http://www.arl. noaa.gov/ready/hysplit4.html, NOAA Air Resources Laboratory, Silver Spring, MD, USA). We calculated the daily trajectories for each sample. The prevailing trajectories were the northwesterlies observed during the sampling 
Fig. 4 Average size distribution of individual PAH compounds and total PAHs measured in winter except W-5 sample
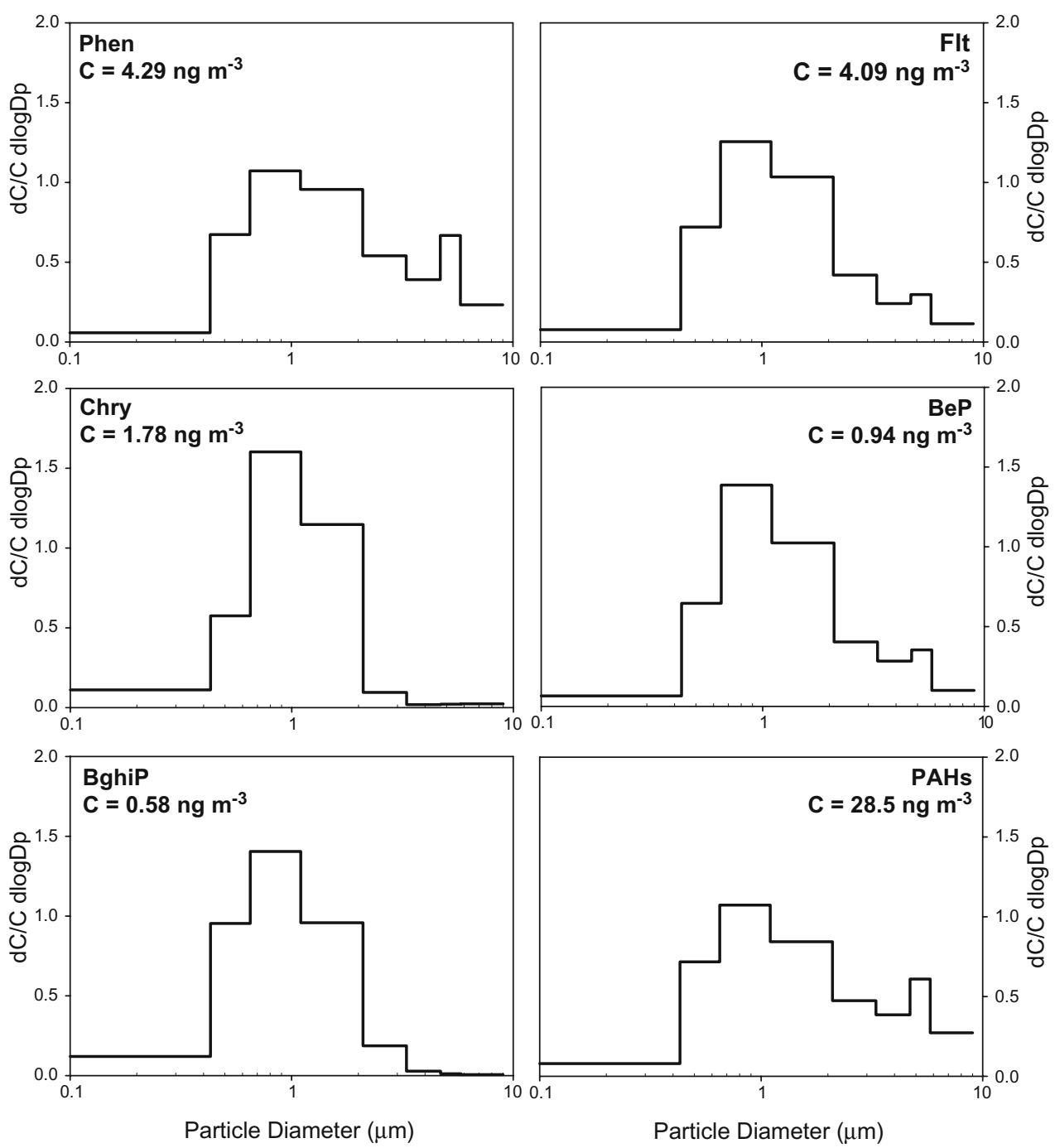

period in winter as shown in Fig. 5b. However, the trajectories were variable in summer (Fig. 5a). Thus, the more aged PAHs emitted from outside of Seoul (notably, North Korea and China as suggested by Lee and Kim 2007) might be attributed to the shift to the larger particle size in the fine mode. On the other hand, the dry deposition velocity of larger particles is higher than smaller particles in the measured size range. However, with the peak size range of $0.1-1-\mu \mathrm{m}$, the dry deposition velocities are usually at minimum and do not change much (Yun et al. 2002; Lee et al. 2006a). Thus, the effect from dry deposition would be small.

Another possible explanation for the larger particle size in winter than summer is that the droplet-mode PAHs in winter came from mixing (or absorption) of PAHs and other soluble pollutants after cloud processing. Venkataraman et al. (1999) explained that droplet-mode particles are likely to contain more aerosol water than condensation-mode particles, and this could result in higher absorption of PAHs into droplet-mode particles. Venkataraman et al. (1999) also suggested that the absorption into droplet mode for lowerMW PAH compounds, which have smaller octanol-water partitioning coefficients, were higher than that for higherMW PAHs. However, this MW dependency was not shown in this study as shown in Fig. 4. Thus, it is likely that the size shift to the large size in winter was mainly due to longer residence time.

The particulate PAH size distributions have been measured at Seoul by Lee et al. (2006a) in the summer of 1999 and Bae et al. (2002) in the winter of 2000, respectively, with the same impactor and a coarse particlerotating impactor for the particle size range of less than $0.43-100-\mu m$. In the summer of 1999 , three peaks were observed: $0.43-0.65,2.1-3.3$, and $5.8-10-\mu \mathrm{m}$ size ranges, respectively. In the winter of 2000 , two peaks were observed: $0.43-0.65-\mu \mathrm{m}$ in the fine mode and 5.8-9.0- $\mu \mathrm{m}$ in the coarse mode, respectively. In their measurements, no seasonal shift of the fine mode peak was observed. Further, no peak in the $2-3-\mu \mathrm{m}$ size range was observed in the winter sample. It is not clear why the peak size in the winter 
Fig. 5 Air parcels movement during the sampling period in $\mathbf{a}$ summer and $\mathbf{b}$ winter
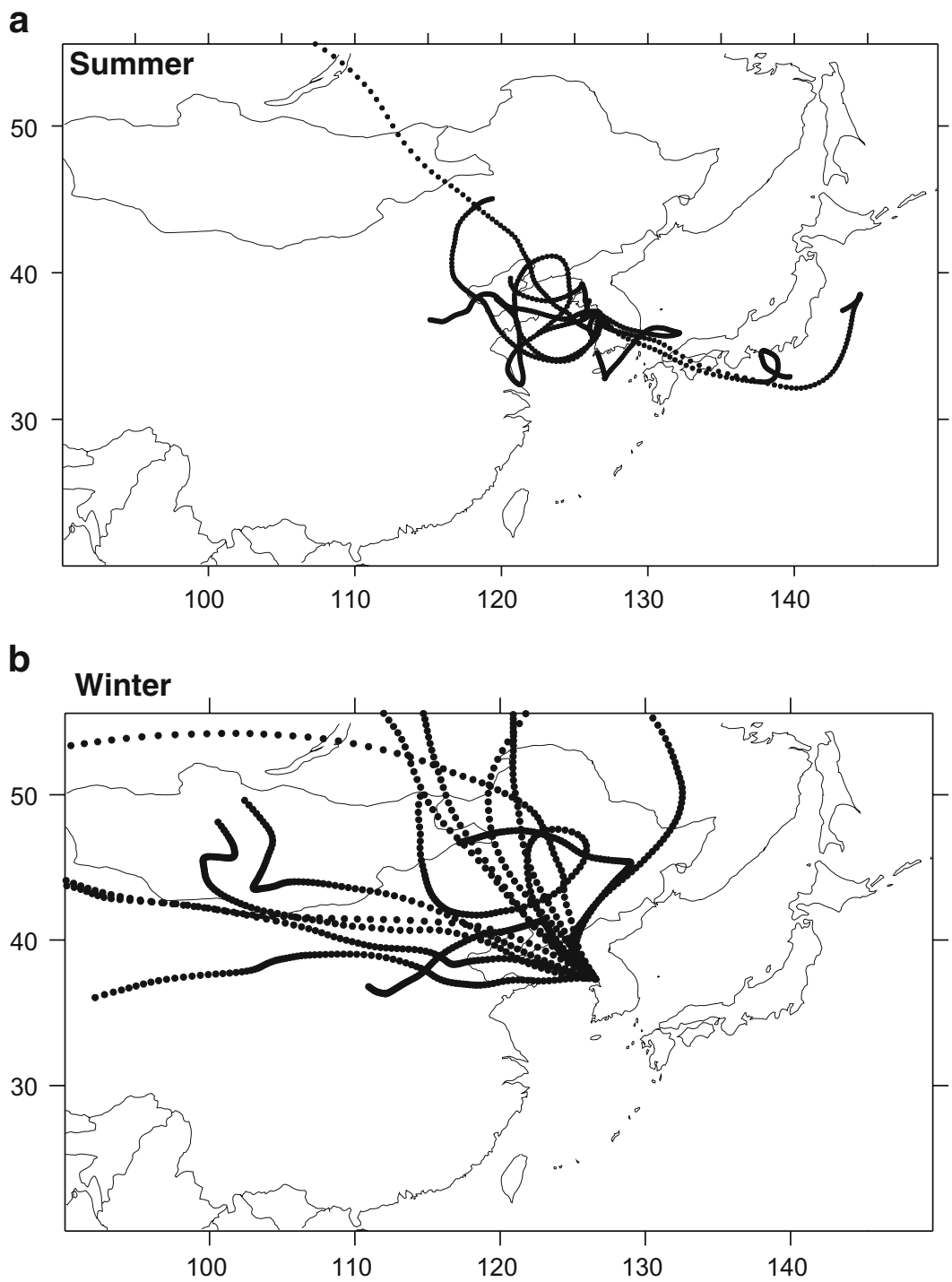

of 2000 was the same with the other summer samples (1999 and 2003).

\section{Source diagnostic ratios}

An important characteristic of PAHs is that the compositions of PAHs of various emission sources are different and, thus, enable to identify the major emission sources on the sampling site. For example, the concentration of Phen is high in a coal residential source profile, BghiP and pyrene (Pyr) for gasoline and diesel vehicles, and Chry for natural gas. Furthermore, low molecular compounds are higher for the coal power plant, middle MW compounds for the coal coke oven, and Flt and Pyr for biomass burning (Lee and Kim 2007). Source diagnostic ratios of PAHs reported in the literatures are applied to distinguish major PAH sources observed in this study. Since PAHs in the fine-mode particles are mainly from anthropogenic sources and we want to know why the size distributions of PAHs in the fine mode were different by season, the source diagnostic ratios of PAHs in the size ranges of $0.43-0.65$ and $0.65-1.1-\mu \mathrm{m}$ diameter in summer and winter are shown in Fig. 6 along with the previously reported values.

Figure 6 shows the source diagnostic ratios values: (a) benzo(a)pyrene (BaP)/BghiP, (b) Phen/antracene (Anthr), (c) benzo(a)anthracene (BaA)/Chry, and (d) BeP/ $\mathrm{BaP}$. The $\mathrm{BaP} / \mathrm{BghiP}$ ratios obtained in this study were higher in winter. The average $\mathrm{BaP} / \mathrm{BghiP}$ ratios in summer were in the range of gasoline $(0.3-0.4)$ and diesel $(0.46-$ $0.81)$ vehicle emissions, while the ratios in winter indicated the influence of coal-related emissions (0.9-6.6). The Phen/ Anthr ratios (Fig. 6b) in summer had no trend, but the ratios in winter were rather in the ranges for gasoline (3.4-8) and diesel (7.6-8.8) emissions. Figure 6c shows the BaA/Chry ratios. The lower values of $\mathrm{BaA} / \mathrm{Chry}$ ratios in summer were in the range of gasoline vehicles $(0.28-1.2)$ and were 
Fig. 6 The source diagnostic ratios a $\mathrm{BaP} / \mathrm{BghiP}$, b Phen/ Antr, c BaA/Chry, and d BeP/ $\mathrm{BaP}$ (Simcik et al. 1999)

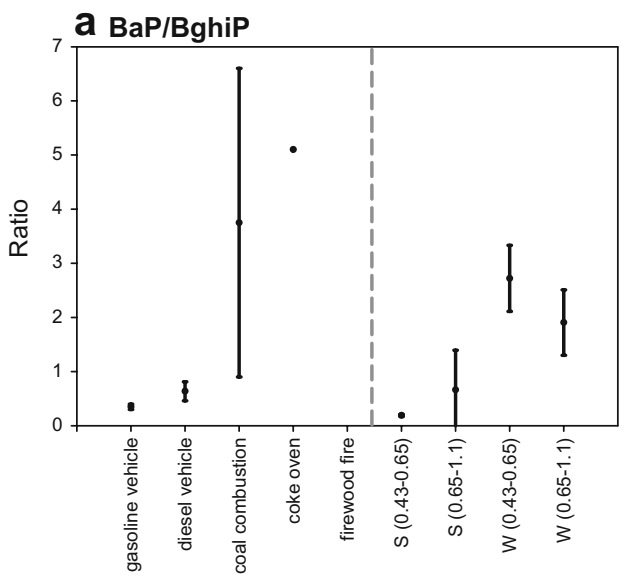

b Phen/Anthr

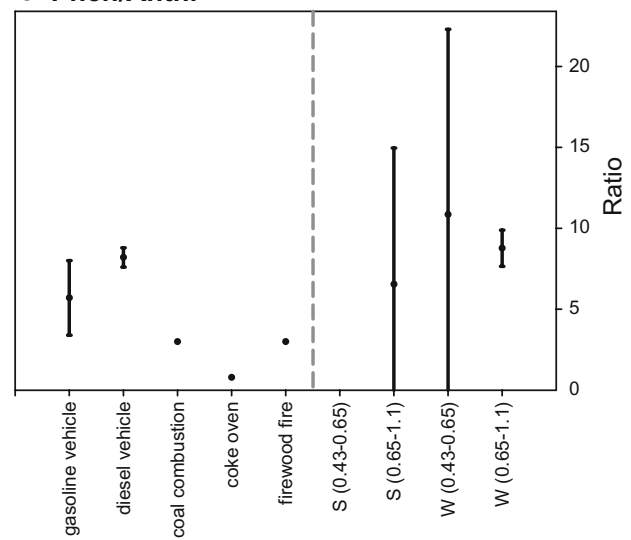

d BeP/BaP

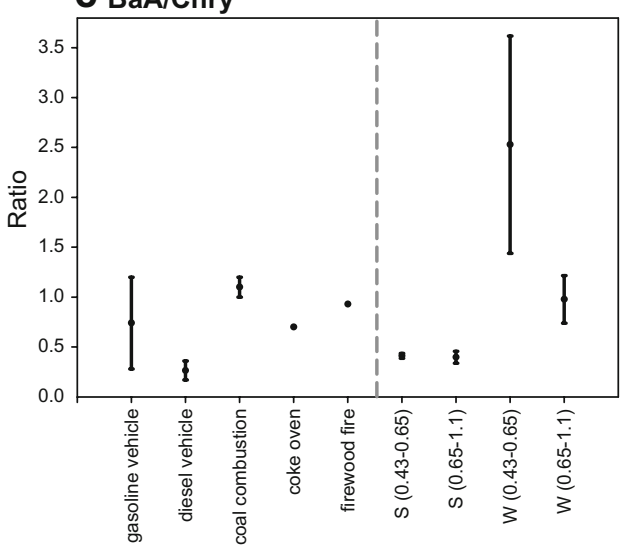

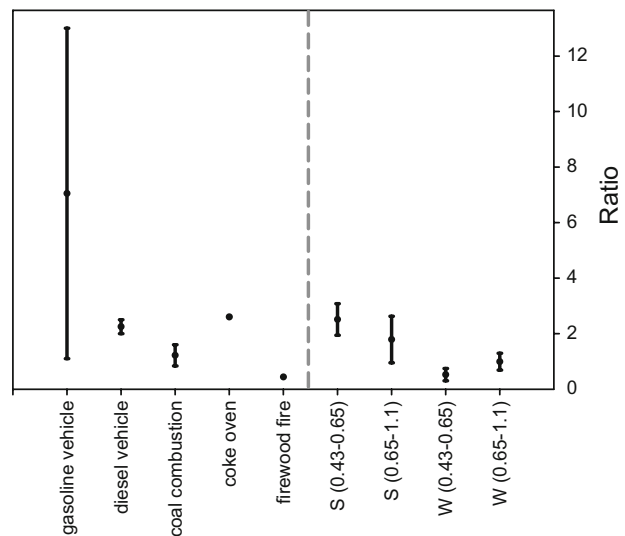

close to the ratios of the diesel vehicles $(0.17-0.36)$. On the other hand, the average $\mathrm{BaA} / \mathrm{Chry}$ ratios in winter belonged to the range of coal combustion and coke ovens (0.6-1.2), firewood fire (0.9), and gasoline vehicles (0.28-1.2). In case of the $\mathrm{BeP} / \mathrm{BaP}$ ratios (Fig. $6 \mathrm{~d}$ ), the higher values in summer compared to winter were on the range of diesel (2-2.5) and gasoline (1.1-13) vehicle emissions. The lower values of $\mathrm{BeP} / \mathrm{BaP}$ ratio in winter were closed to the value of coal-related emission (0.84-1.6) and firewood fire (0.44).

In brief, source diagnostic ratios of PAHs show the major source of $\mathrm{PAH}$ in fine particles were gasoline and diesel vehicles in summer while coal-related emissions and firewood fire in winter. The Ministry of Environment in Korea has limited the use of solid fuel and heavy oils for heating and cooking in Seoul since 1985 and strongly enforced the rule since 1995 (Ministry of Environment Korea 2005). Thus, the amount of coal consumption for residential, industrial, and commercial sectors at Seoul has been rapidly decreased since 1990, and the usage of coal has been negligible since 1995 . Thus, the influence of coal emission in winter might be originated by transport of
PAHs from the outside of Seoul rather than local emission sources. Similar observation was observed from the CMB result by Lee and Kim (2007).

As Lima et al. (2005) have pointed out, however, the source identification approach based on the diagnostic ratios is not a conclusive one and should be used carefully because the diversity of fuels and combustion conditions would produce variations in the ratios. Further, note that there are wide variations of the ratio values. Thus, the use of the various diagnostic ratios should be combined with other approaches to enhance the capability of discerning the sources of PAHs.

Implications of the seasonal variation of the peak size range in the fine-mode particles

Size distribution of ambient particles is an important parameter that determines several aerosol properties such as wet and dry deposition velocity and absorption and scattering coefficients of aerosols. To further study the effects of the seasonal change of the peak size between summer and winter, dry deposition fluxes were estimated 
based on the observed particle size distributions and meteorological parameters. The Sehmel and Hodgson model (Sehmel and Hodgson 1978) was used to calculate size-dependent dry deposition velocities based on the measured meteorological conditions in summer and winter. Inputs to the model include wind speed, atmospheric stability, ambient temperature, and particle density and size. Particle density was assumed as $1 \mathrm{~g} \mathrm{~cm}^{-3}$. The surface roughness height of $0.001 \mathrm{~cm}$ and a stable condition were used. Details on the model application are given in Lee et al. (2006a). The Sehmel and Hodgson model used in this study has been widely used to estimate size-dependent dry deposition velocity. Its results have been compared with the measurements for PAHs (Lee et al. 2006a) and heavy metals (Yun et al. 2002), and those were in fair agreement.

Figure 7 shows the estimated dry deposition fluxes in summer and winter, calculated by multiplying the PAHs concentration and the estimated dry deposition velocity at each size range. The estimated total dry deposition flux in summer was $0.28 \mu \mathrm{g} \mathrm{m}^{-2} \mathrm{day}^{-1}$, while that in winter was $1.22 \mu \mathrm{g} \mathrm{m}^{-2}$ day $^{-1}$. Although the estimated total dry deposition flux in winter was more than four

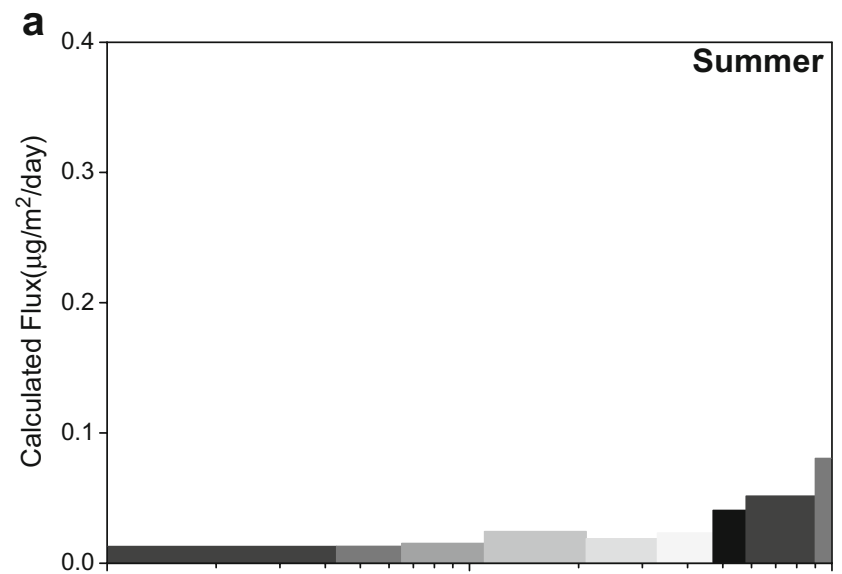

b

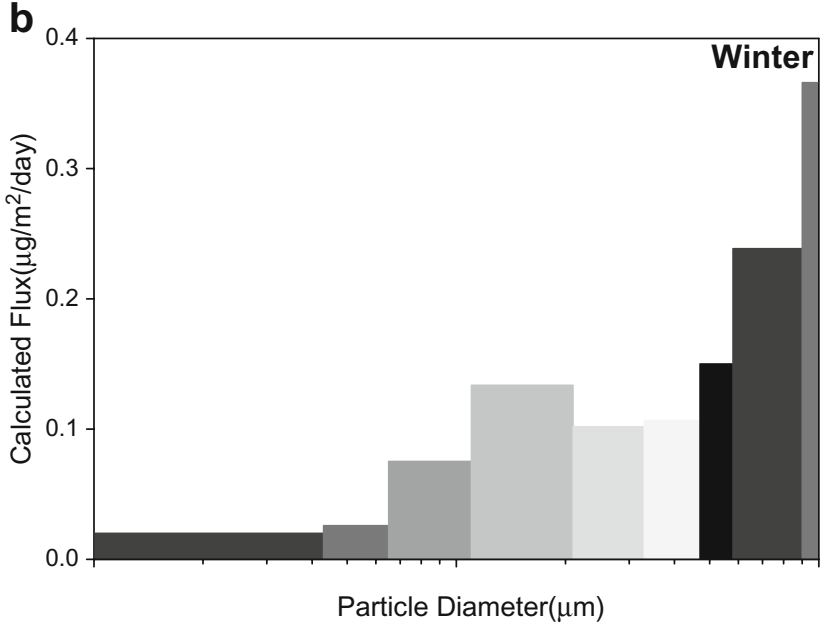

Fig. 7 The estimated size dependent dry deposition fluxes in a summer and b winter, 2003 at Seoul times higher than that in summer, the peak range for the dry deposition fluxes at both seasons in the fine mode was the same, $1.1-2.1-\mu \mathrm{m}$ in diameter. This is due to the strong size dependency of the dry deposition velocity. Generally, the dry deposition velocity shows a minimum in the particle size range of $0.1-1.0-\mu \mathrm{m}$ (Lee et al. 2006a) and becomes higher with larger particles. Thus, both peak size ranges in the fine-mode particles in summer and winter had not shown a noticeable effect on the dry depositin fluxes. Though not shown, the dry deposition flux calculations were carried out for various hypothetical size distributions, and it turned out that the coarse-mode particles dominated the total dry deposition flux.

Particle size is an important parameter that determined the optical properties of the atmosphere. In several climate models and atmospheric general circulation models, aerosol effects are included (see, for example, Kanakidou et al. 2005). In most models, however, particle size is fixed. For example, in the developmental version of the fourth generation Canadian Centre for Climate Modelling and Analysis Atmospheric General Circulation Model (Bäumer et al. 2007), the sizes of OC particles were fixed to 0.2 and $2.0 \mu \mathrm{m}$ in diameter for fine and coarse mode, respectively. Furthermore, Takemura et al. (2000) used a single size for carbonaceous aerosols including OC and EC. They assumed the size to be dependent on the ambient relative humidity. Takemura and Nakajima (2002) showed that the mass extinction coefficient of carbonaceous aerosols from a savanna forest fire was strongly dependent on relative humidity and, thus, aerosol diameter. For the change of mode radius from 0.100 to $0.312 \mu \mathrm{m}$, the mass extinction coefficient changed from 4.63 to $61.57 \mu \mathrm{m} \mathrm{m}^{2} \mathrm{~g}^{-1}$ (Takemura and Nakajima 2002). Therefore, it is warranted to further study the effect of the seasonal aerosol peak size change on the estimated atmospheric optical properties in the models such as the general circulation models.

\section{Summary}

The atmospheric size distributions of particulate PAHs up to $10 \mu \mathrm{m}$ in diameter were measured at Seoul in the summer and winter of 2003. The average PM10 concentration in summer was $85.8 \mathrm{\mu g} \mathrm{m}^{-3}$, which ranged from 65.1 to $117 \mathrm{~g} \mathrm{~m} \mathrm{~m}^{-3}$, and in winter was $97.0 \mu \mathrm{g} \mathrm{m}^{-3}$, which ranged from 45.5 to $223 \mu \mathrm{g} \mathrm{m}^{-3}$, respectively. The concentrations of total PAHs ranged from 4.32 to $5.48 \mathrm{ng} \mathrm{m}^{-3}$ in the summer and from 25.6 to $35.9 \mathrm{ng} \mathrm{m}^{-3}$ in the winter, respectively. The PAH concentrations in winter were about one order higher than those in summer. For both seasons, about a half (41$65 \mathrm{wt} \%$ ) of the PAH concentrations were found on submicrometer particles $\left(D_{\mathrm{p}}<1.1 \mu \mathrm{m}\right)$ and an average $75 \mathrm{wt} \%$ on fine particles $\left(D_{\mathrm{p}}<2.1 \mu \mathrm{m}\right)$. 
The size distributions of individual PAH compounds were bimodal with the peaks in the $0.43-0.65-\mu \mathrm{m}$ size range in the fine mode and in the $4.7-5.8-\mu \mathrm{m}$ range in the coarse mode in summer. In winter, the average size distributions of individual PAH compounds were unimodal or weakly bimodal with the peak in the $0.65-1.1-\mu \mathrm{m}$ size range in the fine mode and in the 4.7-5.8- $\mu \mathrm{m}$ range in the coarse mode. In summer, the mass fractions of the peak range in the fine mode for higher-MW PAH compounds were higher than those for the lower-MW PAH compounds. On the contrary, in the coarse mode, the mass fractions of the peak range for lower-MW PAH compounds were higher than for higherMW PAH compounds. It indicates that the difference of gasto-particle partitioning in the atmosphere due to the difference of MW might affect the size distribution of PAH compounds in summer with higher temperature. The less prominent peak in the coarse mode in winter can be attributed to the lower ambient temperature and, thus, weak gas-to-particle partitioning compared to the summer samples.

The seasonal variation of the peak size range might be caused by two factors: higher condensation amount of aged PAHs due to longer residence time in the atmosphere or resize distribution of PAHs after cloud processing. Based on the air parcel trajectory analysis and the dependency of the fine mode peak height on MW, it is likely that the size shift to the large size in winter was mainly due to longer residence time.

Based on the previously reported source diagnostic ratios of PAHs for the major emission sources, the identification of major PAHs sources for the observed PHAs composition in fine particles was tried. In summer, gasoline and diesel vehicles were identified as the major source of PAH, while coal-related emissions and firewood fire were identified as the major sources in winter for fine particles.

The particle size change might cause variations of several aerosol properties. The seasonal variation of the peak size ranges in the fine particles had not shown noticeable effects on the dry depositin fluxes due to the dominance of the dry deposition flux by coarse particles. However, it is was speculated that the seasonal peak size change might affect significantly the optical properties of the atmosphere due to the variation of the mass extinction coefficient with particle size.

Acknowledgment This work was supported from the National Research Laboratory Program (no. R0A-2006-000-10221-0) funded by the Korea Science and Engineering Foundation. The authors thank to NOAA, USA, for the backward trajectory analysis service.

\section{References}

Aceves M, Grimalt JO (1993) Seasonally dependent size distributions of aliphatic and polycyclic aromatic hydrocarbons in urban aerosols from densely populated areas. Environ Sci Technol 27:2896-2908

Allen JO, Dookeran NM, Smith KA, Sarofim AD, Taghizadeh K, Lafleur AL (1996) Measurement of Polycyclic Aromatic Hydrocarbons associated with size-segregated atmospheric aerosols in Massachusetts. Environ Sci Technol 30:1023-1031

Agency for Toxic Substances and Disease Registry (1995) Toxicological profile for polycyclic aromatic hydrocarbons. Agency for Toxic Substances and Disease Registry, Atlanta

Bae SY, Yi SM, Kim YP (2002) Temporal and spatial variations of the particle size distribution of PAHs and their dry deposition fluxes in Korea. Atmos Environ 36:5491-5500

Bäumer D, Lohmann U, Lesins G, Croft B (2007) Parameterizing the optical properties of carbonaceous aerosols in the Canada Centre for Climate Modeling and Analysis Atmospheric General Circulation Model with impacts on global radiation and energy fluxes. J Geophys Res 112:D10207

Bi XH, Sheng GY, Peng PA, Zhang ZQ, Fu JM (2005) Size distribution of n-alkanes and polycyclic aromatic hydrocarbons (PAHs) in urban and rural atmospheres of Guangzhou, China. Atmos Environ 39:477-487

Chan LY, Kwok WS (2000) Vertical dispersion of suspended particulates in urban area of HongKong. Atmos Environ 34:4403-4412

Kanakidou M, Seinfeld JH, Pandis SN, Barnes I, Dentener FJ, Facchini MC, van Dingenen R, Ervens B, Nenes A, Nielsen CJ, Swietlicki E, Putaud JP, Balkanski Y, Fuzzi S, Horth J, Moortgat GK, Winterhalter R, Myhre CEL, Tsigaridis K, Vignati E, Stephanou EG, Wilson J (2005) Organic aerosol and global climate modelling: a review. Atmos Chem Phys 5:1053-1123

Kawanaka Y, Matsumoto E, Sakmoto K, Wang N, Yun SJ (2004) Size distributions of mutagenic compounds and mutagenicity in atmospheric particulate matter collected with a low-pressure cascade impactor. Atmos Environ 38:2125-2132

Lee JY, Kim YP (2007) Source apportionment of the particulate PAHs at Seoul, Korea: Impact of long range transport to a megacity. Atmos Chem Phys 7:3587-3596

Lee JY, Kim YP, Yi SM (2006a) Size distributions and dry deposition fluxes of particulate Polycyclic Aromatic Hydrocarbons (PAHs) at several sites in Korea in 1999. Environ Eng Sci 23:393-404

Lee JY, Kim YP, Kang CH, Ghim YS, Kaneyasu N (2006b) Temporal trend and long-range transport of particulate PAHs at Gosan in Northeast Asia between 2001 and 2004. J Geophys Res 111:D11303

Lima ALC, Farrington JW, Reddy CM (2005) Combustion-derived polycyclic aromatic hydrocarbons in the environment - a review. Environ Forensics 6:109-131

Miguel AH, Friedlander SK (1978) Distribution of benzo[a]pyrene and coronene with respect to particle size in Pasadena aerosols in the submicron range. Atmos Environ 12:2407-2413

Ministry of Environment, Korea (2005) Annual report of air quality in Korea 2004. Ministry of Environment, South Korea

Offenberg JH, Baker JE (1999) Aerosol size distributions of polycyclic aromatic hydrocarbons in urban and over-water atmospheres. Environ Sci Technol 33:3324-3331

Pandis SN, Seinfield JH, Pilinis C (1990) The smog-fog-smog cycle and acid deposition. J Geophys Res 95:18489-18500

Pierce RC, Katz M (1975) Dependency of polynuclear aromatic hydrocarbon content on size distribution of atmospheric aerosols. Environ Sci Technol 9:347-353

Sehmel GA, Hodgson WH (1978) A model for predicting dry deposition of particles and gases to environmental surfaces. DOE Report PNL-SA-6721, Pacific Northwest Laboratory, USA.

Seinfeld JH, Pandis S (1998) Atmospheric chemistry and physics. Wiley, New York

Sicre MA, Marty JC, Saliot A, Aparicio X, Grimalt J, Albaiges J (1987) Aliphatic and aromatic hydrocarbons in different sized 
aerosols over the Mediterranean Sea: occurrence and origin. Atmos Environ 21:2247-2259

Simcik MF, Eisenreich SJ, Lioy PJ (1999) Source apportionment and source/sink relationships of PAHs in the coastal atmosphere of Chicago and Lake Michigan. Atmos Environ 33:5071-5079

Takemura T, Nakajima T (2002) Single-scattering albedo and radiative forcing of various aerosol species with a global three-dimensional model. J Clim 15:333-352

Takemura T, Okamoto H, Maruyama Y, Numaguti A, Higurashi A, Nakajima T (2000) Global three-dimensional simulation of aerosol optical thickness distribution of various orgins. J Geophys Res 105:17853-17838

United Nations Environment Programme (2002) Regionally based assessment of persistent toxic substances. Central and North East Asia regionally report. Global Environment Facility, URR. Available at: http://www.chem.unep.ch/pts/regreports/C\&NE\% Asia\%20full\%20report.pdf van Vaeck L, van Cauwenberghe K (1978) Cascade impactor measurements of the size distribution of the major classes of organic pollutants in atmospheric particulate matter. Atmos Environ 12:2229-2239

Venkataraman C, Friedlander SK (1994) Size distributions of polycyclic aromatic hydrocarbons and elemental carbon. 2. Ambient measurements and effects of atmospheric processes. Environ Sci Technol 28:563-572

Venkataraman C, Thomas S, Kulkarni P (1999) Size distributions of polycyclic aromatic hydrocarbons - gas/particle partitioning to urban aerosols. J Aerosol Sci 30:759-770

Yun H-J, Yi SM, Kim YP (2002) Dry deposition fluxes of ambient particulate heavy metals in a small city, Korea. Atmos Environ 36:5449-5458

Zhou J, Wang T, Huang Y, Mao T, Zhong N (2005) Size distribution of polycyclic aromatic hydrocarbons in urban and suburban sites of Beijing, China. Chemosphere 61:792-799 